\section{Commentary: Cisplatin-induced nephrotoxicity following cytoreductive surgery and heated intraoperative chemotherapy for malignant pleural mesothelioma}

\author{
Shawn S. Groth, MD, MS, and R. Taylor Ripley, MD
}

Despite improvements in survival with aggressive multimodal therapy for malignant pleural mesothelioma (MPM), approximately $35 \%$ of these patients ultimately develop recurrent disease within the ipsilateral hemithorax (67\% of all recurrences), implicating a need for more efficacious methods of local tumor control. ${ }^{1}$ A number of intraoperative adjunctive therapies have been used in an attempt to reduce recurrence rates and extend survival, including heated povidone-iodine, ${ }^{2}$ photodynamic therapy, ${ }^{3}$ and heated intraoperative chemotherapy (HIOC). ${ }^{4}$ In one study that examined use of cisplatin HIOC in a group of patients with MPM with a favorable risk profile, HIOC led to significantly longer disease-free (27.1 vs 12.8 months) and overall survival (35.3 vs 22.8 months). ${ }^{4}$ The efficacy of HIOC must be balanced against its toxicities.

The major dose-limiting toxic effect of HIOC with cisplatin is nephrotoxicity. In this issue of the Journal, Hod and colleagues ${ }^{5}$ examined the incidence, predictors, and consequences of acute kidney injury (AKI) in their series of 503 patients who underwent cytoreductive surgery (with or without cisplatin-based HIOC) over a 9-year period. They found that $48.3 \%$ of patients who underwent HIOC had some degree of AKI; $3.2 \%$ required hemodialysis. Stage 3 AKI was associated with a 2.7 -fold increased

\footnotetext{
From the Division of General Thoracic Surgery, The Michael E. DeBakey Department of Surgery, Baylor College of Medicine, Houston, Tex.

Disclosures: The authors reported no conflicts of interest.

The Journal policy requires editors and reviewers to disclose conflicts of interest and to decline handling or reviewing manuscripts for which they may have a conflict of interest. The editors and reviewers of this article have no conflicts of interest.

Received for publication June 8, 2020; revisions received June 8, 2020; accepted for publication June 9, 2020; available ahead of print June 27, 2020.

Address for reprints: R. Taylor Ripley, MD, Division of General Thoracic Surgery, Department of Surgery, Baylor College of Medicine, 6620 Main St, Suite 1325, Houston, TX 77030 (E-mail: R.Taylor.Ripley@bcm.edu).

J Thorac Cardiovasc Surg 2021;161:1519-20

$0022-5223 / \$ 36.00$

Copyright (c) 2020 by The American Association for Thoracic Surgery

https://doi.org/10.1016/j.jtcvs.2020.06.058
}

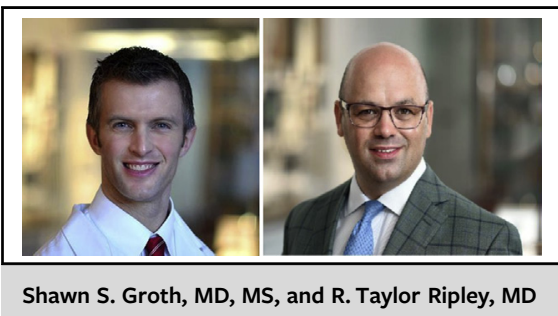

CENTRAL MESSAGE
Multimodal strategies are
needed to minimize the risk and
severity of acute kidney injury
after cytoreductive surgery and
platinum-based heated intrao-
perative chemotherapy for
mesothelioma.

risk of death on multivariable analysis, highlighting the implications of postoperative complications on long-term survival.

Clinicians and researchers at the Brigham and Women's Hospital have a tradition of excellence in advancing the care of MPM and should be congratulated on their dedication to minimizing adverse events. The mechanism of cisplatin-induced nephrotoxicity is complex and likely involves uptake of cisplatin metabolites into renal tubular cells, which leads to activation of cell-signaling pathways that promote apoptosis and a vigorous inflammatory response. Cisplatin may also directly injure the renal vasculature, thereby promoting ischemic injury. ${ }^{6}$ Because of its multifactorial etiology, single-modal renal-protective strategies are ineffective; multimodal management is needed. Indeed, the group at the Brigham found that amifostine alone did not provide adequate renal protection. ${ }^{7}$ However, the combination of amifostine, sodium thiosulfate, and a proactive perioperative fluidmanagement strategy was beneficial in reducing the incidence of AKI. ${ }^{8}$

There are many unanswered questions regarding HIOC for MPM. The optimal duration and combination of chemotherapy agents of HIOC is unknown. Although Hod and colleagues identified risk factors for AKI, further studies are needed regarding patient selection for HIOC versus other modalities of treatment. Finally, whether the addition of other renal protective agents that have been studied in vitro and in preclinical animal models of 
cisplatin-induced nephrotoxicity (eg, antitumor necrosis factor- $\alpha$, mitogen-activated protein kinase inhibitors, and cyclin-dependent kinase 2 inhibitors) to an established renal-protective strategy (eg, fluid replacement, amifostine, and sodium thiosulfate) can reduce the incidence and severity of AKI further following cisplatin-based HIOC is unknown.

\section{References}

1. Baldini EH, Recht A, Strauss GM, DeCamp MM Jr, Swanson SJ, Liptay MJ, et al. Patterns of failure after trimodality therapy for malignant pleural mesothelioma. Ann Thorac Surg. 1997;63:334-8.

2. Lang-Lazdunski L, Bille A, Papa S, Marshall S, Lal R, Galeone C, et al. Pleurectomy/decortication, hyperthermic pleural lavage with povidone-iodine, prophylactic radiotherapy, and systemic chemotherapy in patients with malignant pleural mesothelioma: a 10-year experience. J Thorac Cardiovasc Surg. 2015; 149:558-65; discussion 565-6.

3. Friedberg JS, Culligan MJ, Mick R, Stevenson J, Hahn SM, Sterman D, et al. Radical pleurectomy and intraoperative photodynamic therapy for malignant pleural mesothelioma. Ann Thorac Surg. 2012;93:1658-65; discussion 1665-7.

4. Sugarbaker DJ, Gill RR, Yeap BY, Wolf AS, DaSilva MC, Baldini EH, et al. Hyperthermic intraoperative pleural cisplatin chemotherapy extends interval to recurrence and survival among low-risk patients with malignant pleural mesothelioma undergoing surgical macroscopic complete resection. J Thorac Cardiovasc Surg. 2013;145:955-63.

5. Hod T, Freedberg K, Motwani SS, Chen M, Frendl G, Leaf DE, et al. Acute kidney injury after cytoreductive surgery and hyperthermic intraoperative cisplatin chemotherapy for malignant pleural mesothelioma. J Thorac Cardiovasc Surg. 2021;161:1510-8.

6. Pabla N, Dong Z. Cisplatin nephrotoxicity: mechanisms and renoprotective strategies. Kidney Int. 2008;73:994-1007.

7. Zellos L, Richards WG, Capalbo L, Jaklitsch MT, Chirieac LR, Johnson BE, et al. A phase I study of extrapleural pneumonectomy and intracavitary intraoperative hyperthermic cisplatin with amifostine cytoprotection for malignant pleural mesothelioma. J Thorac Cardiovasc Surg. 2009;137:453-8.

8. Tilleman TR, Richards WG, Zellos L, Johnson BE, Jaklitsch MT, Mueller J, et al. Extrapleural pneumonectomy followed by intracavitary intraoperative hyperthermic cisplatin with pharmacologic cytoprotection for treatment of malignant pleural mesothelioma: a phase II prospective study. J Thorac Cardiovasc Surg. 2009;138:405-11.
See Article page 1510.

\section{Commentary: Winning the battle for local control without losing war for survival against malignant pleural mesothelioma}

\author{
Alejandro Bribriesco, MD
}

Malignant pleural mesothelioma (MPM) remains vexing despite decades of therapeutic refinement. Curative local control involves cytoreductive surgery (CS) by extrapleural

\footnotetext{
From the Section of Thoracic Surgery, Department of Thoracic and Cardiovascular Surgery, Heart Vascular and Thoracic Institute, Cleveland Clinic, Cleveland, Ohio. Disclosures: The author reported no conflicts of interest.

The Journal policy requires editors and reviewers to disclose conflicts of interest and to decline handling or reviewing manuscripts for which they may have a conflict of interest. The editors and reviewers of this article have no conflicts of interest.

Received for publication June 29, 2020; revisions received June 29, 2020; accepted for publication June 29, 2020; available ahead of print July 10, 2020.

Address for reprints: Alejandro Bribriesco, MD, Section of Thoracic Surgery, Department of Thoracic and Cardiovascular Surgery, Heart, Vascular and Thoracic Institute, Cleveland Clinic, 9500 Euclid Ave/Mailstop J4-1, Cleveland, OH 44195 (E-mail: bribria@ccf.org).

J Thorac Cardiovasc Surg 2021;161:1520-2

$0022-5223 / \$ 36.00$

Copyright (c) 2020 by The American Association for Thoracic Surgery

https://doi.org/10.1016/j.jtcvs.2020.06.092
}

Check for updates

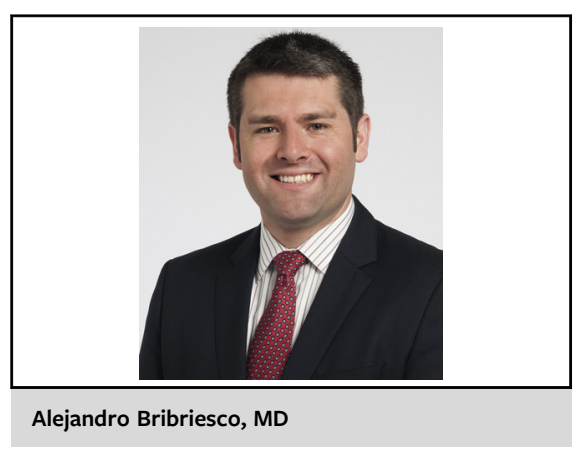

CENTRAL MESSAGE

Curative treatment of mesothe-

lioma includes aggressive local

disease control. To optimize sur-

vival, pursuit of microscopic tu-

mor destruction must be

balanced by physiologic cost to

the patient.

pneumonectomy (EPP) or lung-sparing techniques like pleurectomy/decortication (PD). As part of multimodality therapy, the goal of CS is macroscopic complete resection. ${ }^{1,2}$ Intraoperative adjuncts to increase tumor destruction include intracavitary therapy with hyperthermic 